La

Révolution

française

\section{La Révolution française}

Cahiers de l'Institut d'histoire de la Révolution française

$9 \mid 2015$

Citoyenneté, république, démocratie dans la France de la Révolution

\title{
Les catéchismes politiques français (1789-1914)
}

French political catechisms (1789-1914)

Jean-Charles Buttier

\section{OpenEdition}

Journals

Édition électronique

URL : http://journals.openedition.org/lrf/1441

DOI : $10.4000 /$ Irf. 1441

ISSN : 2105-2557

Éditeur

IHMC - Institut d'histoire moderne et contemporaine (UMR 8066)

Référence électronique

Jean-Charles Buttier, "Les catéchismes politiques français (1789-1914) », La Révolution française [En ligne], 9 | 2015, mis en ligne le 16 novembre 2015, consulté le 04 mai 2019. URL : http://

journals.openedition.org/Irf/1441; DOI : 10.4000/Irf.1441

Ce document a été généré automatiquement le 4 mai 2019.

(c) La Révolution française 


\title{
Les catéchismes politiques français (1789-1914)
}

French political catechisms (1789-1914)

\author{
Jean-Charles Buttier
}

\section{NOTE DE L'ÉDITEUR}

Jean-Charles Buttier, Les catéchismes politiques français (1789-1914), Thèse préparée à l'IHRF sous la direction de Jean-Clément Martin et soutenue en Sorbonne le 9 mars 2013 devant un jury composé de Sylvie Aprile, Yves Déloye, Jean-Clément Martin, Michèle Riot-Sarcey et Pierre Serna, son président.

\section{Présentation des sources}

1 Parmi la riche littérature politique publiée dans le contexte de la réunion des États généraux se distinguent des ouvrages composés sous la forme d'une succession de questions et de réponses. Ces livres sont les héritiers de la catéchèse chrétienne qui connut une progressive laïcisation dans les années 1770 . Considérer le catéchisme politique comme un genre littéraire structuré par une pédagogie politique permet d'isoler des thèmes récurrents, des variations langagières ainsi que des transferts intertextuels.

2 Les catéchismes diocésains ne partagent pas le projet d'éducation politique ici étudié et ont donc été exclus du périmètre de cette recherche. Il s'est produit une politisation de la catéchèse avec la politique de diffusion par Napoléon d'un Catéchisme à l'usage des églises de l'empire français paru en 1806. Le projet n'est pas de vulgariser une doctrine mais d'asseoir la fidélité à l'empereur sur des commandements insérés dans le contenu dogmatique du catéchisme. Une tentative proche de politisation de la catéchèse a eu lieu à la fin du XIX ${ }^{\mathrm{e}}$ siècle lorsque certains catéchismes diocésains intègrent des commandements électoraux. 
${ }^{1}$ Là encore, ces catéchismes ne sont pas écrits dans le même objectif de vulgarisation politique.

3 Une fois ces réserves posées, les recherches bibliographiques ont permis d'étoffer le corpus des catéchismes de l'époque révolutionnaire qui avaient déjà été identifiés par Michel Manson ${ }^{2}$, Hans Christan Harten ${ }^{3}$ ou encore Jean Hébrard ${ }^{4}$ dans leurs travaux respectifs. Produits dans le contexte du Bicentenaire de la Révolution française, ces recherches ne portaient pas sur la postérité du genre. Voici pourquoi j'ai étudié les catéchismes politiques français édités pendant tout XIX ${ }^{e}$ siècle. J'ai choisi de n'étudier que les catéchismes français, à l'exception de rééditions étrangères de catéchismes parus initialement en France. Des points de comparaison existent car le catéchisme politique n'est pas une spécificité hexagonale ${ }^{5}$ et la production française a fortement influencé l'écriture de catéchismes politiques dans d'autre pays.

4 La Première Guerre mondiale marque une rupture avec la quasi disparition du genre littéraire apparu avec la Révolution française. Alors que le marxisme réinterprété par Jules Guesde avait été vulgarisé sous la forme de catéchismes socialistes dans les années 1880-1890, la fondation du parti communiste français n'a entraîné la publication que d'un seul Petit catéchisme bolchevik ${ }^{6}$ en 1919 pour défendre l'adhésion à la III Internationale. Les auteurs qui veulent faire œuvre de vulgarisation politique n'utilisent plus le terme catéchisme dans leur titre et la forme question / réponse est délaissée. Cette littérature politique correspond étroitement au long XIXe siècle qui s'étend de 1789 à 1914.

5 Le corpus de catéchismes politiques ainsi constitué s'élève à 815 livres ce qui représente un total de 390 titres différents accompagnés de leurs rééditions parfois très nombreuses. L'objectif visé n'est pas l'exhaustivité, par définition impossible à atteindre puisque cette recherche porte sur des livres dont l'existence dépend des aléas de la conservation. La constitution d'un corpus de sources conséquent tend toutefois à refléter le plus fidèlement possible la variété de ces livres politiques.

\section{Problématique, méthodes d'analyse des sources et plan du doctorat}

6 La thèse que je défends est que l'unité et l'enracinement du genre du catéchisme politique s'expliquent par la large diffusion d'une pédagogie politique. Celle-ci fonde une écriture destinée à permettre la vulgarisation politique qui doit déboucher sur l'apprentissage de la citoyenneté. Un auteur (ou un éditeur) répond par l'écriture de son ouvrage à l'attente du public (ou plus précisément à ce qu'il pense être l'attente du groupe de lecteurs qu'il conçoit comme le public potentiel). J'ai fait le choix d'étudier ces livres de la Révolution française à la Première Guerre mondiale pour appréhender les phénomènes de mémoire des textes qui voyagent dans le temps, portés par des supports qui en font varier la réception. Etudier ces ouvrages de vulgarisation sur une aussi longue durée permet d'en comprendre le contenu mais aussi la perception que les auteurs avaient des lecteurs supposés.

7 L'intérêt de cette approche est d'appréhender les catéchismes politiques comme un genre, terrain d'observation privilégié des évolutions thématiques sur la longue durée. Considérer les catéchismes politiques comme un corpus fermé est la condition pour voir comment une même pédagogie politique a pu évoluer tout en étant traversée de constantes thématiques et rhétoriques. 
8 Une telle étude nécessitait au préalable un travail d'édition de sources aboutissant à une typologie pour historiciser le contenu des catéchismes. Le genre catéchistique est le fruit d'un transfert pédagogique qui s'opère entre les années 1770 , celles de la laïcisation et les premières années de la Révolution française marquées par la politisation de cette rhétorique. Le catéchisme politique est, à partir de 1794 / an II (apogée du temps de l'écriture), quasiment cantonné au domaine scolaire comme le montre sa reconnaissance officielle en 1796 (an IV) et la large diffusion des catéchismes primés sous le Directoire. La Seconde République est marquée par la transmission de textes révolutionnaires et de catéchismes des années 1830 et surtout par l'utilisation du catéchisme pour former les nouveaux électeurs. Les auteurs républicains écrivent des catéchismes pour défendre et enraciner la Troisième République. Cette littérature n'est pas le monopole des Républicains comme l'illustre la diversification des opinions politiques défendues et en particulier l'importance tardive des catéchismes socialistes en particulier guesdistes. Le catéchisme politique fut un moyen de propagande étroitement lié aux périodes révolutionnaires et républicaines ce qui fait du Premier Empire, de la Restauration et du Second Empire des creux dans son histoire éditoriale. Le projet partagé d'éducation politique s'insère dans un contexte d'instabilité institutionnelle, que ce soit pendant une Révolution ou bien lors de l'enracinement de la République.

9 L'étude du contenu des ouvrages mobilise des méthodes empruntées à l'analyse littéraire : esthétique de la réception et intertextualité. Cette approche a ensuite été croisée avec une analyse lexicométrique pour étudier systématiquement les titres, avertissements et tables des matières. Le travail de typologie effectué au préalable a abouti à la constitution d'un échantillon représentatif de 44 catéchismes qui ont été analysés lexicométriquement. L'analyse lexicométrique du contenu confirme l'hypothèse de la constitution progressive d'un genre littéraire dont le fondement est une mémoire intertextuelle faite de références internes au corpus. J'ai pu observer un jeu de transmission des textes de la Première à la Deuxième puis à la Troisième République avec un moment clé dans les années 1830. Parler de genre littéraire ne veut pas dire qu'il y ait unicité de l'objet mais que l'hétérogénéité n'empêche pas que des faisceaux de correspondances se rejoignent. Les auteurs se citent, se plagient, se font mutuellement référence en inscrivant leur écriture dans un genre bien défini. C'est ce qui justifie une approche par corpus fermé qui permet de voir l'évolution du genre par l'étude des variations textuelles ${ }^{7}$. Les livres se situant à la croisée de l'intention de l'auteur et de la demande du lecteur, l'analyse de ce genre littéraire devient un point d'observation sur la politisation du peuple au XIX ${ }^{\mathrm{e}}$ siècle.

10 La première partie de mon doctorat s'intitule «Un genre très diversifié à l'histoire heurté » et consiste en une présentation chronologique des textes accompagnée d'une explicitation de l'intention des auteurs et éditeurs.

11 La deuxième partie intitulée «Analyser le contenu des catéchismes » porte sur l'analyse de contenu en croisant celle-ci avec une typologie plus fine liée au contexte d'usage des catéchismes qui a fortement varié. L'échantillon représentatif des 44 catéchismes a été étudié à l'aide de logiciels de lexicométrie, Lexico 3 ou Coocs. Cela permet d'adosser l'interprétation des textes à une analyse de statistique textuelle qui fait ressortir les termes les plus employés. Je me suis intéressé ensuite aux phénomènes de transmission mémorielle, les catéchismes politiques fonctionnant comme un genre littéraire traversé de relations intertextuelles. 
12 La troisième partie s'intitule justement « Un genre littéraire enraciné » qui aboutit au constat d'un progressif enracinement du genre. Que ce soit sur des courtes ou bien des longues durées, certains catéchismes politiques ont connu une très forte diffusion d'après les rééditions retrouvées. Faire l'histoire du regard historique porté sur les catéchismes politiques vise à reconstituer comment a été progressivement construit l'objet historique. Nous sommes les héritiers d'une historiographie de la fin du XIXe siècle qui s'est intéressée aux catéchismes publiés pendant la Révolution française en les considérants comme un genre mineur. Ces travaux se caractérisent par une acception péjorative du catéchisme politique qui vient de la difficulté à dissocier l'élémentaire du vulgaire.

\section{Enjeux de la recherche}

13 Le catéchisme, par sa forme interrogative, entraîne une distinction entre celui qui interroge et celui qui répond. Cela induit dans le cadre de la catéchèse religieuse une hiérarchie très marquée entre le catéchiste qui détient la vérité dogmatique et le catéchumène qui doit l'apprendre, l'interrogation se résumant souvent à un artifice rhétorique ne servant qu'à vérifier l'orthodoxie de la foi du catéchumène. La principale différence entre la catéchèse chrétienne et les catéchismes politiques tient à l'absence d'une institution stricto sensu qui ait porté ce discours. Dans son acception politique, le terme doit cependant être limité au livre, il serait abusif de parler d'une catéchèse politique compte tenu de l'extrême diversité des doctrines que nous avons présentées. Alors que la vérité du catéchisme chrétien reposait sur l'autorité du maître (qui se laïcise progressivement), il y eut au contraire une multiplicité d'institutions, d'intermédiaires et de récepteurs du catéchisme politique en fonction des différents contextes d'utilisation. La frontière s'efface souvent entre celui qui sait et celui qui apprend.

Marc Angenot oppose un sens dénotatif à un sens péjoratif du terme propagande dans son étude sur la propagande guesdiste :

J'appelle propagande tout ce qui a argumenté pendant plus d'un siècle le bien fondé de «l'idée " socialiste, tout ce qui a visé à "convertir» les masses et à faire «trembler les bourgeois» et qui - sous forme de brochures, d'éditoriaux, de chroniques - forme la masse de l'imprimé militant, loin devant les théories de la «science $»^{8}$.

15 J'ai fait l'histoire du catéchisme politique mais aussi l'histoire de l'histoire du catéchisme politique qui a donné une perception largement négative de ce type d'ouvrages jugés dogmatiques, emploi qui reste encore le plus répandu aujourd'hui. Adopter la vision descriptive de la propagande proposée par Marc Angenot permet d'écarter l'écran péjoratif qui occulte souvent la claire perception de la pédagogie politique qui sous-tend le genre et de voir que celui-ci n'est pas oxymorique.

Le catéchisme politique s'adapte au public visé en se vulgarisant mais il doit en retour mettre le public en situation de recevoir une éducation politique à même de le transformer en citoyen. Dans quelle mesure le lecteur a lui aussi connu une adaptation pour être réceptif au message ainsi développé? Il est mis en situation de recevoir ce discours puisque la construction en questions / réponses permet de se repérer facilement dans le texte. De plus, l'argument de l'efficacité de la pédagogie catéchistique constitutive du genre est l'importance de l'apprentissage par cœur. L'ouvrage devient ainsi un support de mémorisation mais aussi d'enseignement (lorsque le public visé est scolaire) ou de lecture collective, utilisation souvent prônée ou rendue possible par une évolution du 
format (l'In-folio par exemple). L'objet livre est en adéquation avec ce projet de large diffusion par son prix modeste.

17 La définition de vulgariser est double : il s'agit d'une part de répandre largement, de faire entrer dans les habitudes du grand public, de l'ensemble d'une société. Vulgariser, c'est aussi et surtout mettre à la portée de tous, des notions, des théories de différents domaines du savoir. Le catéchisme politique incarne ainsi une époque marquée par la croyance en la capacité de l'individu à s'émanciper politiquement par ses lectures.

\section{NOTES}

1. Yves DÉLOYE, Les voix de Dieu. Pour une autre histoire du suffrage électoral: le clergé catholique français et le vote XIX ${ }^{e}-X X^{e}$ siècle, Paris, Fayard, 2006, $407 \mathrm{p}$.

2. Michel MANSON, Les livres pour l'enfance et la jeunesse sous la Révolution, Paris, INRP, 1989, 272 p.

3. Hans Christian HARTEN, Les écrits pédagogiques sous la Révolution, Paris, INRP, 1989, 148 p.

4. Jean HÉBRARD, "Les Catéchismes de la première Révolution", dans Colporter la Révolution, Montreuil, 1989, Ville de Montreuil-Bibliothèque Robert Desnos, p. 74-81

5. Consulter à ce sujet le premier numéro de La Révolution française intitulé Les catéchismes républicains, 1 | 2009 [en ligne]. URL : http://lrf.revues.org/107 mis en ligne le 13 novembre 2009.

6. René REYNAUD, Petit catéchisme bolchevik, Paris, l'Emancipatrice, 1919, 28 p.

7. Roger CHARTIER, Au borde de la falaise. L'histoire entre certitudes et inquiétudes, Paris, Albin Michel, 1998 , p. 57.

8. Marc ANGENOT, La propagande socialiste. Six essais d'analyse de discours, Montréal, Les éditions Balzac, 1997, p. 9.

\section{INDEX}

Mots-clés : catéchisme politique, pédagogie politique, vulgarisation, politisation, morale, éducation-civique

Keywords : political catechism, political pedagogy, popularization, politicization, morals, civics 